\title{
'|||||||||||||||||||||||||||||||||||||||||||||||||||||||||||||||||.
}

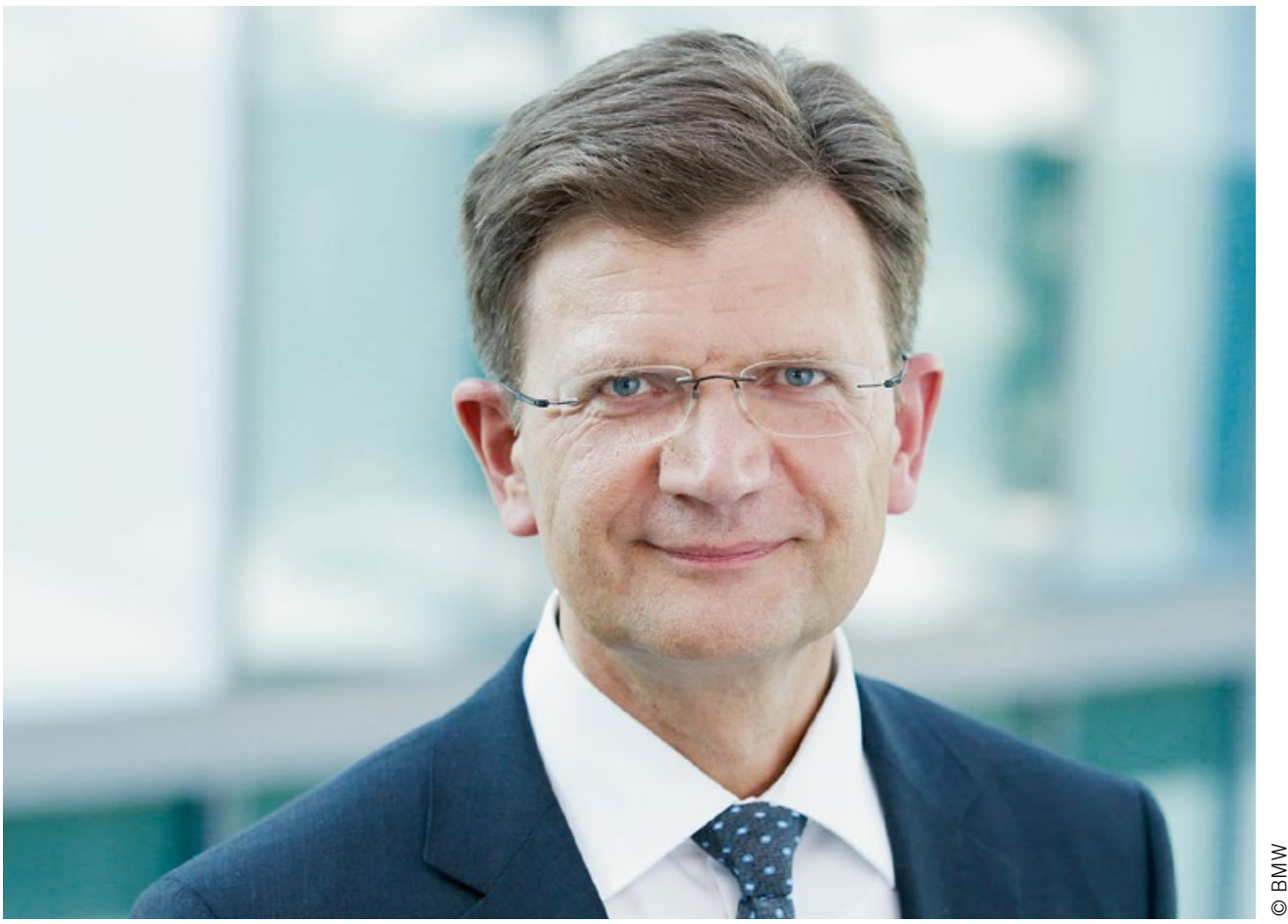

Dipl.-Ing. Klaus Fröhlich

Mitglied des Vorstands, Entwicklung, BMW AG,

ATZ-Beirat

\section{Umbruch der Automobilindustrie}

Die individuelle Mobilität und ihre Industrialisierung befinden sich in einem Umbruch. Das Automobil wird sich in der nächsten Dekade stärker verändern als in den letzten fünfzig Jahren. Dieser Wandel wird einerseits durch eine weltweit sich beschleunigende, uneinheitliche Regulation bezüglich Verbrauch, Emissionen und Sicherheit getrieben. Andererseits ändern sich auch die Kundenanforderungen fundamental: Sie fordern eine „Seamless Connectivity“ und eine intelligente Unterstützung in allen Fahrsituationen durch ein smartes Fahrzeug. Hier orientiert sich der Kunde an seinen Möglichkeiten im Internet und mit dem Smartphone.

Die fundamentalen Fortschritte bei alternativen Antrieben und digitaler Vernetzung ermöglichen in diesen Bereichen neue Lösungsräume. Dieser Umbruch stellt die tradierten Automobilhersteller vor große Herausforderungen. Sie müssen hohe Einmalaufwände und Kosten der neuen Technologien beherrschen. Gleichzeitig wirkt sich die begrenzte Zahlungsbereitschaft der Kunden auf die Ertragskraft aus.

Elektrifizierte Antriebe und vernetzte Fahrzeuge erlauben neuen Wettbewerbern den Markteintritt. Ein gravierender Kompetenzumbau von der Hard- zur Software und neue Prozesse in Richtung deutlich beschleunigter Abläufe sind erforderlich. Im Gegensatz zum heute vorherrschenden Businessto-Business-Geschäftsmodell ist in Zukunft das beste Kundenverständnis erfolgskritisch.
Wir bei der BMW Group sehen in diesem Wandel aber auch eine große Chance. So haben wir bereits in den letzten Jahren hohe Vorleistungen in die Industrialisierung der auch langfristig nebeneinander bestehenden Antriebe wie Verbrennungsmotor, Elektroantrieb und Brennstoffzelle investiert. Ebenfalls sind wir mit der frühen Markteinführung unserer „Connected Drive Services“ Trendsetter. Und mit dem neuen BMW 7er haben wir bei Fahrerassistenz und Bedienbarkeit einen neuen Aufsatzpunkt in Richtung hochautomatisiertes Fahren gesetzt.

Auch bezüglich Kompetenzen und Prozessen hat der Umbau längst begonnen. Vieles konnten wir mit BMW i pilotieren: Unsere Softwarehäuser wachsen rapide; zur Sicherstellung der notwendigen Kompetenzen bauen wir dazu ein weltweit aufgestelltes Netzwerk auf. Den notwendigen Ausbau der strategischen Kooperationen sowohl mit Lieferanten und anderen OEMs als auch verstärkt mit Partnern aus Consumer-Elektronik, IT und Mobilitätgeschäft werden wir fortsetzen - bis hin zur Beteiligung an Start-ups über BMW i Ventures. Zusätzlich lernen wir mit den neuen Vertriebsmodellen und Mobilitätsangeboten von BMW i den Kunden in seinen Bedürfnissen noch besser kennen.

Für unsere Industrie, aber auch für die ATZ heißt das: Nie war es spannender und vielfältiger als heute, die Mobilitätsbedürfnisse unserer Kunden auch in Zukunft erfüllen zu können. 